\title{
The generality of free-recall: I. Subjective organization as an ability factor
}

DAVID S. GORFEIN, CLAUDIA BLAIR, AND CHARITY ROWLAND, DEPARTMENT OF PSYCHOLOGY, NEW COLLEGE, Sarasota, Fla. 33578

Using Bousfield's intertrial repetition measure as a score representing $S$ 's tendency to subjectively organize material in free-recall, a group of $S$ 's were tested on a variety of materials in a multiple trial free-recall paradigm. Evidence obtained did not support a hypothesis of subjective organization being a general individual difference ability factor.

An increasing portion of the research ir free-recall has been devoted to the role of subjective organization (SO). Tulving (1962), Ehrlich (1965), and Bousfield \& Bousfield (1966) have proposed metrics for determining the amount of SO. Numerous studies have demonstrated that performance in Free-recall trials correlates with SO (cf. Tulving, 1968). Following the suggestion of Melton (1967) we attempted to see if this hypothesized process variable (SO) can be established as an individual difference variable.

Materials. Forty-item lists of four different materials were used: CCCs of $50 \%$ Association Value (Witmer, 1935), CVCs (Full range of $\mathrm{m}^{\prime}$ (Noble, 1961) from 0.17 to 4.14), 10 most frequent words from each of Bousfield's (1953) 4-category lists, 40 unrelated words matched for Thorndike-Lorge (1944) frequency with the Bousfield words.

Subjects. Thirty-seven paid volunteers served in all conditions but the CVC condition in which one $\mathrm{S}$ was lost.

Procedure. The Ss were divided at random into two groups. The CCC, Categorized (CAT), and word lists were tested on three consecutive evenings with one group receiving the list in that order while the other had the reverse order. CVCs were tested approximately four weeks later. Testing was at the same hour in adjacent rooms for the $\mathrm{CCC}$ and unrelated word lists. The categorized word list and CVC list were tested with both groups together. Items were projected visually at a 1 -sec rate. Four minutes were allowed for recall. Seven trials were run in a session with items presented in new scrambled orders on each trial.

Results and Discussion. In scoring free recall data, each group was scored separately and individual scores were converted to $\mathrm{T}$-scores $(\mathrm{T}=50+10 \mathrm{Z})$ before correlations on the combined samples were run.

Clustering Scores. For each consecutive pair of trials by an $S$ the number of items that occurred in adjacent positions were counted, e.g., if on Trial $1 \mathrm{~S}$ reported (in order): dog, cat, work, symbol, hearth, and on Trial 2 reported: level, work, cat, dog, hearth,- the score observed would be one. This number would then be divided by a modification of Bousfield \& Bousfield's (1966) estimate of the expected number of pairs

$$
\mathrm{E}=\frac{2 \mathrm{C}(\mathrm{C}-1)}{\mathrm{hk}}
$$

where $\mathrm{C}=$ number of items in common on the two trials and $\mathrm{h}$ and $k$ represent the number recalled on trials $N$ and $N+1$, respectively. The 2 is a constant since the formula ${ }^{1}$ as given by Bousfield represents only the likelihood that a pair will occur on consecutive trials in the same order (cat-dog on both and not as we scored it-dog-cat or cat-dog). Thus our clustering measure is $C R=O / E$ where $O$ represents the observed number of pairs. In order to achieve reliability for the analyses reported the $C R$ measure represents average $\mathrm{CR}$ over the last three trials

$$
\frac{\mathrm{CR}_{5,6},+\mathrm{CR}_{6,7}}{2}
$$

Separate CRs were computed for each material.

Since CR scores are an average, an estimate of their reliability can be determined by taking the correlation of $\mathrm{CR}_{5,6}$ and $\mathrm{CR}_{6,7}$

\begin{tabular}{lccc} 
Inter-correlations of Cluster Measures & \\
& \multicolumn{3}{c}{ Table } \\
& \multicolumn{3}{c}{ A. Obtained Correlations } \\
\cline { 2 - 4 } & CVC & WORDS & CAT \\
\hline CCC & 39 & 08 & 08 \\
CVC & & 46 & 47 \\
WORDS & & & 30 \\
\hline & \multicolumn{3}{c}{ B. Corrected for Attenuation } \\
\hline & CVC & WORDS & CAT \\
\hline CCC & 50 & 12 & 12 \\
CVC & & 60 & 61 \\
WORDS & & & 44 \\
\hline
\end{tabular}

and correcting it with the Spearman-Brown formula (McNemar, 1962 , p. 150). The corrected estimated reliability of the cluster measure for CCC is .68 , for CVCs .89 , for Words .68 and for CAT .67.

Table 1A shows the intercorrelations of the four cluster measures. The correlations are limited by their respective reliabilities. McNemar (1962, p. 153) suggests an estimate of what the "true" correlation is when the obtained correlation is attenuated by unreliability:

$$
r_{t t}=r_{x y}\left(r_{x x}\right)^{-1 / 2\left(r_{y y}\right)^{-1 / 2}}
$$

Table 1B shows the obtained correlations when this formula is applied to the data in Table 1A. Only the two correlations rCCC, Words and rCCC, CAT are not significant. These nonsignificant correlations indicate that the ability to cluster is specific to the kind of material to be clustered. The correlation between CCCs and $\mathrm{CVCs}$ can be considered to be of similar materials, i.e., low meaningfulness since the CVC list covers about the full-range of Noble's Scale.

Table 2 shows that the CR appropriate to the material, in general, correlates significantly with trial scores on that material.

Table 3 more fully explores the possibility of a generalized clustering tendency. Since all the CR scores had been converted to $\mathrm{T}$-scores and thus were comparable in mean and standard deviation it was possible to obtain a median CR score for each S (MCR). We then correlated MCR with trial performance for the four types of material. The most interesting findings involve comparing Tables 2 and 3 for CCCs. On Trials $1-4$ the correlations in Table 2 are a good deal larger than those in 3 but after this point they do not differ greatly. It is not possible at this time to interpret this finding, but it should be worthy of repeating the procedure to see if it can be replicated.

The correlations of the individual $C R$ scores with MCR are for CR (CCC) .49, for CR (CVC) .84, CR (Words) .71 and for CR (CAT) .68 .

In summary, free-recall of four different materials was tested across Ss to see if these were consistent individual differences in

Table 2 CR (app.) as Predictor of Trial T Scores ${ }^{2,3}$

\begin{tabular}{lccccccc} 
& 1 & 2 & 3 & 4 & 5 & 6 & 7 \\
\hline CCCs & 46 & 45 & 33 & 26 & 43 & 48 & 47 \\
CVCs & 45 & 63 & 63 & 63 & 56 & 63 & 61 \\
WORDS & 31 & 47 & 55 & 58 & 63 & 64 & 56 \\
CAT & 25 & 39 & 45 & 53 & 57 & 55 & 48 \\
\hline
\end{tabular}


Table 3

Median CR (MCR) as Predictor of Trial T Scores 2,3

\begin{tabular}{llllllll} 
& 1 & 2 & 3 & 4 & 5 & 6 & 7 \\
\hline CCCs & 23 & 30 & 24 & 20 & 43 & 48 & 37 \\
CVCs & 47 & 59 & 61 & 59 & 58 & 62 & 65 \\
WORDS & 36 & 50 & 54 & 62 & 58 & 63 & 51 \\
CAT & 36 & 50 & 49 & 64 & 56 & 55 & 58 \\
\hline
\end{tabular}

the ability to organize the material for recall. Results indicate that there is not a generalized ability that could be called subjective organization. For most free-recall studies (those involving similar materials such as words and some CVCs) it is possible to get a generalized measure of clustering ability.

\section{REFERENCES}

BOUSFIELD, A. K., \& BOUSFIELD, W. A. Measurement of clustering and of sequential constancies in repeated Free-recall. Psychol. Rep., 1966, 19, 935-942.

BOUSFIELD, W. A. The occurrence of clustering in the recall of randomly arranged associates. J. gen. Psychol., 1953, 49, 229-240.
EHRLICH, S. Le rôle de la structuration dans l'apprentissage verbal. Psychologie Francaise, 1965, 10, 119-146.

McNEMAR, Q. Psychological statistics (3rd ed.). New York: Wiley, 1962.I,

MELTON, A. W. Individual differences and theoretical process variables. In R. M. Gagné (Ed.), Learning and individual differences, Columbus: Charles E. Merrill, 1967.

NOBLE, C. E. Measurements of association value (a) rated associations (a') and scaled meaningfulness ( $\mathrm{m}$ ') for the $2100 \mathrm{CVC}$ combinations of the English alphabet. Psychol Rep., 1961, 8, 487-521.

THORNDIKE, E. L., \& LORGE, I. The teacher's word book of 30,000 words. New York: Teachers College, 1944.

TULVING, E. Theoretical issues in free recall. In T. R. Dixon and D. L. Horton (Eds.), Verbal behavior and general behavior theory. Englewood Cliffs: Prentice-Hall, 1968.

WITMER, L. R. The association value of three-place consonant syllables. $J$. genet. Psychol, 1935, 47, 337-360.

\section{NOTES}

1. We are indebted to Professor Charles Lyons of the Mathematics staff for checking the derivation of this formula.

2. For CVCs: $\mathrm{N}=36 \mathrm{r}>.43 \mathrm{p}<.01 ; \mathrm{r}>.33 \mathrm{p}<.05$

For all other measures: $\mathrm{N}=37 \mathrm{r}>.33 \mathrm{p}<.05 ; \mathrm{r}>.42 \mathrm{p}<.01$

3. All correlations are reported with decimal points omitted. 